\title{
The Potential of Urban Peripheries to Manage the Stress Due to the COVID-19
}

\author{
Mario Fernández Arce, Jonnathan Reyes Chaves, and Huberth Vargas Picado
}

\begin{abstract}
This article focuses on the influence of the urban periphery in human health, particularly, in the management of the COVID-19 disease, which is generated by the SARS-CoV-2 virus. The periphery of cities can serve as an open space that allows people to get out of confinement and practice healthy activities, without risk of contagion. Therefore, routes of urban periphery can be visited by walkers and cyclists currently during pandemic. This publication emphasizes the potential of the Santo Domingo's periphery (which also applies to the cities of San Pablo, San Rafael and San Isidro) as a space for rest, fun, recreation and, fundamentally, as a space that helps managing any disease that requires isolation and confinement. Routes of the studied area were chosen to observe the spatial transformations and recreational activities along them. Those routes are used for physical activity and recreation by both walkers and cyclists.
\end{abstract}

Index Terms - urban periphery, physical activity, COVID19, pandemic, stress.

\section{INTRODUCTION}

This article focuses on the influence of the urban periphery in human health and, mainly, in the management of the COVID-19 disease. The studied area, which includes zones of the three neighboring cantons San Pablo, San Rafael, and San Isidro (Fig. 1), is the periphery of Santo Domingo, San Pablo, San Rafael, and San Isidro. Three routes were traced and traveled to observe the transit of people along them as well as the human activities to cope with the pandemic and reduce its effects.

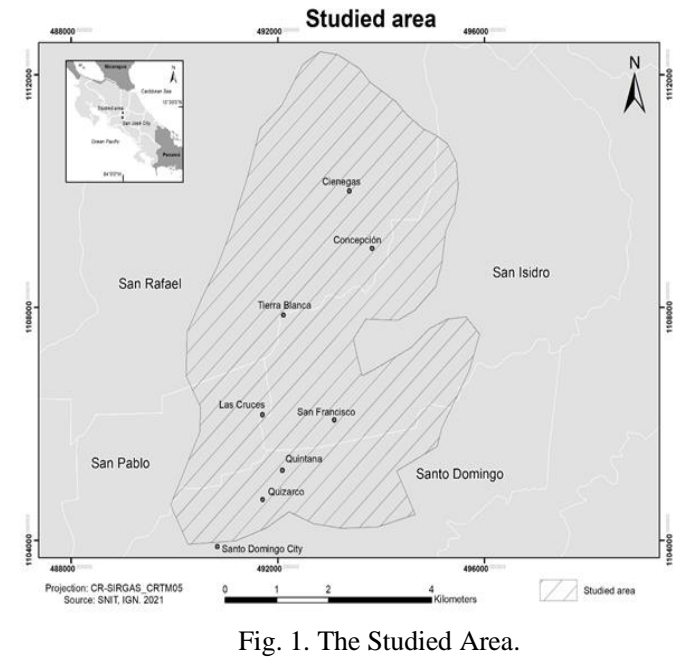

Published on June 16, 2021.

Mario Fernández Arce, Escuela de Geografía, Universidad de Costa Rica, Costa Rica.

(corresponding e-mail: mefernan.mario ${ }^{@}$ gmail.com)

Jonnathan Reyes Chaves, Escuela de Geografía, Universidad de Costa Rica, Costa Rica.

(e-mail: rjonnathan ${ }^{\circledR}$ gmail.com)
The current disease affects all the World's countries and demands social isolation and confinement to avoid contagion. On the other hand, the complex situation generated by the pandemic and the mentioned measures can generate frustration, boredom, depression, weakness, loss of sleep, nervousness, fatigue, and headaches. Since the beginning of the pandemic in Costa Rica, people were encouraged to carry out physical activities but with social distancing and, at the same time, places such as parks and recreation centers for the urban population were closed in order to avoid crowds.

Given this reality, the periphery of cities can serve as an open space that allows people to reduce the confinement and practice healthy activities, without the risk of contagion. Within the social division of the urban space, the peripheries have become territories of diversification and social confrontation. What were once spaces relegated to settlers under marginal conditions, today are attractive areas for the real estate industry and the individuals. People see in these places a set of "consumable" elements, privileged zones, green areas, beautiful landscapes, pure air, optimal conditions for recreation, dispersed habitat, and good access to the city. All these variables are an economic, commercial, and geographic attractive. Peripheral urban places are highly visited by people who seek recreation [1].

One major characteristics of the metropolis and their peripheries is the singularity of socioeconomic processes and the dynamism that characterizes their spatial transformations, marked by a logic of globalization. In the rural world of the Great San Jose Metropolitan Area there are agricultural and forestry activities, conservation areas and a complex communication network that favors physical activity and recreation. The purpose of this investigation was to observe the physical activity of people on selected routes and highlight the potential of the periphery of Santo Domingo (which also applies to the cities of San Pablo, San Rafael and San Isidro) as a space for rest, fun, recreation and, fundamentally, for the management of any disease that requires isolation and confinement. Reflecting on the recognition and valuation that the local population makes of their territory is important, as well as the available resources and the means of appropriation, understood as an intensification in the consumption of the urban peripheries under different interests.

According to [2], recreational activity increased by $291 \%$ in green areas during confinement for COVID-19. They noted

Huberth Vargas Picado, Escuela de Geografía, Universidad de Costa Rica Costa Rica.

(e-mail: hvp.ucr@gmail.com) 
that pedestrians and cyclists intensified physical activity on trails in green areas, suggesting that such spaces facilitated social distancing and indirectly mitigated the spread of COVID-19. To detect behaviors similar to those reported by [2], our group chose routes of the studied area, traced them on Google images and shared them among the investigators for their respective approval were. Once the routes were approved, they were covered by the research group on foot from beginning to end and round trip. The researchers verified the route on their cell phones, took pictures of the sites or aspects of interest and described the processes, dynamism, spatial transformations, and recreational activity along the roads. All the data collected was analyzed and systematized.

According to the observations, the predominant rural landscape in the studied area is agricultural, with an absolute predominance of coffee plantations with a complex network of roads. A major transformation observed is the use of land from farmland to residential zones. The area has excellent views of the Central Valley, which is a great attractive for both residents and tourists. During the tours, the research group verified that walkers and cyclist use the routes for physical activity and recreation.

\section{MethodOlOGY}

This investigation required bibliographic review, selection of observation routes, collection of data and analysis of information (Fig. 2).

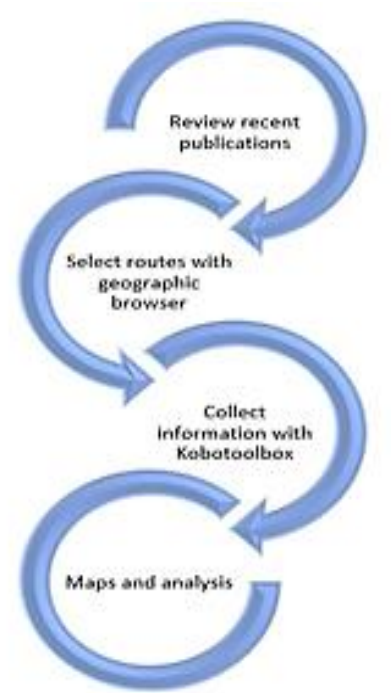

Fig. 2. Methodological steps.

Recent publications were studied to know the psychosocial effects of the current pandemic on people, which include the discomfort caused by social isolation and confinement. The researchers sought valuable information on human behavior during situations similar to the current one in those documents and the recommended activities to face the adversity generated by COVID-19. Due to the interest of addressing the relation between routes and connections established with nearby urban centers, the group studied the northeast periphery of the city of Santo Domingo de Heredia.

Routes close to the Santo Domingo community were chosen to carry out the analysis. Geographic browsers such as Google Earth and Google Maps were used for this selection to determine the possible connections between points and towns with greater precision. Old roads or secondary streets were selected when the Google program suggested the use of busy roads and highways.

Planning the walks included the selection of routes connecting Santo Domingo to nearby cities of neighboring cantons. The criteria for choosing these routes were low vehicular traffic and also open rural spaces where people could walk. Such criteria obey to the interest of observing the flow of people through streets and roads, mainly people engaged in physical and recreational activity. The investigators also required a broad overview of the spaces used by people to manage stress and anxiety derived from confinement caused by COVID-19.

The investigation's third phase included walks along the routes between July and December 2020. During the tours, the research group observed the geographical space, its attractions and its transformation and sought answers to questions about the transit of people through private areas. The researchers paid attention to the transit of people, type of activity and characteristics of the space and took photographs of interesting and attractive elements. Some administrators and foremen of the farms were interviewed during the walks.

\section{RESULT}

\section{A. Pandemics: Effects and Coping Strategies}

When COVID-19 began, health and psychological services organizations warned of its effects, highlighting frustration and boredom from confinement, anxiety related to finances, impact in the general health, loss of mental capacity, disability to think coherently and the increasing difficulty of having mental health services [3]. Other known effects of the pandemic are depression, weakness, lack of sleep, nervousness, tiredness, and headaches. According to these authors, a complex interaction of social, economic, physical, medical, and psychological factors arises from this disease, as happened with the Spanish fever that killed more than 50 million people between 1918 and 1919.

The psychological effects of pandemics are closely intertwined with the physical ones [3]. According to [4], during social isolation and confinement, people tend to be sedentary by spending a lot of time in front of electronic devices, especially cell phones, computers, and television, which can lead to weight gain and disorders associated with an increased cardiovascular risk, such as obesity, increased blood pressure, glucose intolerance and other disorders such as anxiety and depression.

The association between perceived change in exercise and mental health in adults, in response to strategies to mitigate COVID-19 disease was investigated by [5]. Their results indicate that the perceived decrease in physical activity was associated with higher levels of stress and anxiety. His conclusion is that strategies to mitigate the pandemic may be impacting such activity and mental health, generating a higher level of stress and anxiety in those who experience a reduction in physical activity. But, according to them, these relationships are confused with environmental and genetic factors. 
Regarding pandemics and physical activity, COVID-19 has raised concerns about the exercise. Moderate intensity exercises can improve immunity function, cardiovascular health, and attenuate virus activity by reducing inflammatory agents, and can even inhibit inflammation in the early stages [6]. Therefore, and according to [4], it is advisable to maintain a physically active lifestyle routine as a preventive health measure to confront the spread of the Sars-Cov-2 virus. For them, a physically active life and practicing physical exercise is a beneficial measure to improve immunity and face the COVID-19 disease. Cycling was recommended as one of the physical activities to face pandemics [3].

\section{B. Routes of Observation}

As said before, three routes (Fig. 3) were chosen to observe the physical activity, exercise, and recreation of people along them. The names of the routes do not exist officially but were proposed by the researchers. Among their qualities are their high visitation on weekends, their panoramic view of the central valley, the diversity of land uses along them, the presence of rural elements and the low density of population and traffic.

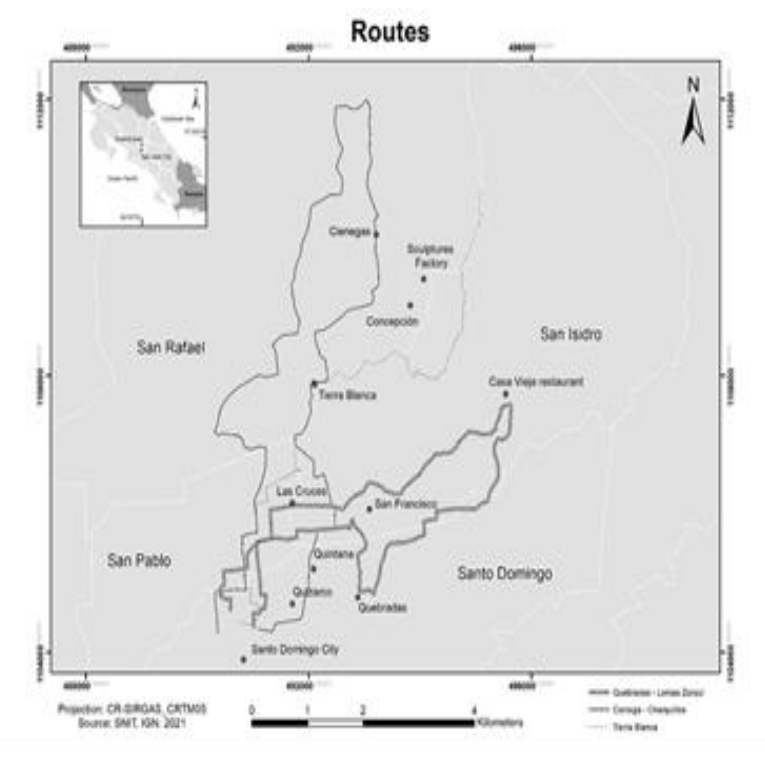

Fig. 3. Routes of Observation.

The first route observed is called Tierra Blanca and is of $22.4 \mathrm{~km}$ long. There are fruit trees, coffee plantations, beautiful views of the Central Valley of Costa Rica (Fig. 4) and an interesting community named Tierra Blanca along this route. This small human settlement is attractive and charming due to the kindness and warmth of its inhabitants. Its geographic center is La Esquina, a point of meeting and social gathering. According to a sign placed there (Fig. 4), grandparents, parents and children have maintained that tradition for more than 100 years in that neighborhood inhabited by cultured, helpful and hard-working people. The sign's information welcomes the visitors and suggest that people meet in La Esquina to talk for hours and spend moments of summer afternoons, probably very pleasant.
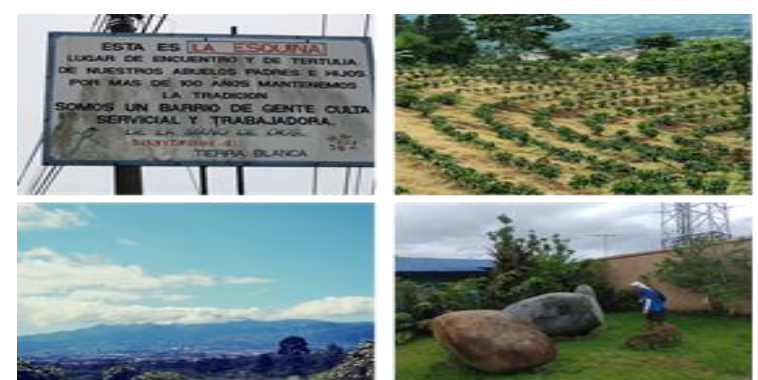

Fig. 4. Spatial elements along the routes. Sign, Coffee plantation, a view of the Central Valley of Costa Rica and the sculpture factory of Concepción. Photos of Jonnathan Reyes.

This practice, once very common throughout the country, unites the members of the community and increases group cohesion, an elementary factor to face challenges, difficulties, threats, and risks. During the visits, the investigators saw travelers in La Esquina, mainly cyclists, sitting there, doing exactly what was mentioned above. For them, such place is a meeting and resting site, where they rest, hydrate, and regain energy in order to successfully complete the trip. The charm of this community invites to stay there for a while, enjoying and resting.

When returning, the tourists, walkers and cyclists can visit Concepción, where they can take a break, eat some in the community's restaurants or see art at the sculptor's factory "El Alquimista" located neat that town (Fig. 3). In this factory, Aquiles Jiménez, the artist, carves the andesite type volcanic rock.

The route Ciénagas - Charquillos is a path of $22.3 \mathrm{~km}$ whose northern segment is more rural and belongs to the San Rafael de Heredia canton. This hike starts in the city of Santo Domingo and passes through Quizarco, La Quintana, Tierra Blanca and Ciénagas. Along the road there are coffee plantations, pastures and a forestall area (Cypress trees). At the northern end, on both sides, there are quiet and lonely places suitable for enjoying the outdoors. During the visits, the researchers saw many people hiking around the place and families sharing a lunch next to the route.

Quebradas - Lomas Zurquí route includes important human settlements throughout its $17.2 \mathrm{~km}$. This path should only be done in dry season because whoever does it must cross a small river on foot; in the rainy season is difficult and dangerous to cross that river. In Quebradas there is nougat factory where the visitor can buy high quality nougat at a very low price. The route includes segments that cross coffee, bean and corn farms. Along the path there are educational centers, residential areas and the Casa Vieja restaurant, which is a good option for having lunch or having a hot or cold drink. Near that restaurant there is a sales position of artisan products where the traveler can find a typical souvenir made of wood or valuable utensils such as wooden artifacts to make coffee.

\section{Physical Activity, Resiliency and Health}

During the hikes, the researchers saw people applying what [4] and [3] recommended to manage the psychological effects associated with the current pandemic. Many people are going out every day, and mainly on weekends, to walk the routes or practice cycling, to leave the confinement for a while and do moderate physical activity that provides well-being and reduces both the level of stress and anxiety. One of the busiest 
sectors is the polygonal area Quizarco-Tierra Blanca-Casa Vieja-Quebradas, which includes segments of the three routes studied (Fig. 5).

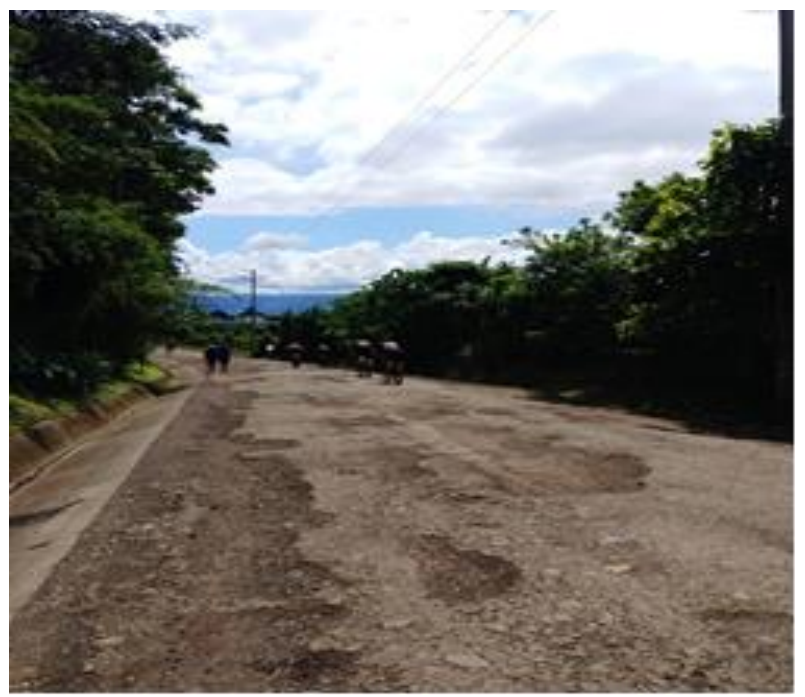

Fig. 5. Group of cyclists and two walkers near Quizarco.

In route Ciénaga-Charquillos, at the entrance to an agricultural farm, dedicated to coffee production, there are two signs of private property. In one sign it is handwritten that both pedestrians and cyclists are welcome to that property (Fig. 6). Such farm is a large area with multiple roads and trails, highly visited by cyclists and hikers. The sign can be interpreted as a support from the owners to those who wants to better handle the adversity generated by the pandemic.

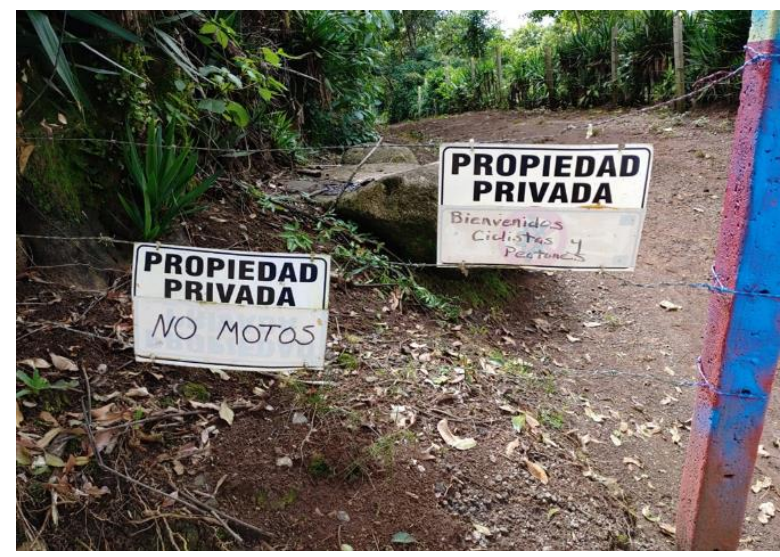

Fig. 6. Signs at the entrance of a private property.

The authors asked an administrator of a coffee farms if hikers and cyclists are allowed to enter his farm. His answer was negative, adding that he ordered to such people to leave the property. But on the farm where the previously mentioned signs, a foreman stated that they are not concerned with citizens entering the farms in order to practice sports and do physical activities because those who enter for these purposes are good people, who far from doing damage, could help to prevent damage. In his opinion, good people help to stop the damage generated by bad people who enter the farms to steal and affect both the property and the crops. This explains the reason why both pedestrians and athletes circulate through the coffee plantations. For the owners, administrators or foremen visitors can help to protect the farm and for these visitors the farms are ideal places because of their panoramic views, stillness, absence of people and flat relief.

Physical and mental health influence human susceptibility to being impacted by threats [7]. The more deteriorated the health of a person, the less strength and interest will have to face the dangers. So true is this that an extremely distressed and desperate person sometimes seeks to self-destruction. On the contrary, physically, and mentally healthy people tend to be optimistic and have a great desire to live. If danger appears, they are confronted with all possible resources, which is called resistance. And they can also draw on coping strategies and skills, which is known as resilience.

Good nutrition, the intake of certain natural and chemical products, the use of masks and physical exercise are typical actions of resistance against the Sars-Cov-2 virus. Those four activities strengthen the immune system of people, reducing the virus's chance to enter in a person because the defenses of the human body are high. This is precisely why children, young people and athletes are less likely to be infected. Besides, if they are infected, the effects on them are very weak. In this way, opposition is offered to the virus and vulnerability is diminished with resistance.

Buying sports equipment such as bicycles, tennis, and clothing to carry out recreational and sports activities to face the pandemic is a very clear example of resilience, since those actions are ways of handling the adverse situation. Going for a walk or riding a bicycle in rural, country, uninhabited places and without crowds, is a resilient activity that reduce the confinement and help to better manage the stress and the anxiety caused by the pandemic. Breathing clean air and walking freely in the countryside, without fear of getting infected, are strategies to face the crisis associated to COVID19. The feeling of freedom when doing this and observing the beautiful panoramic views from different points of the routes visited produce a positive effect on people, which makes people forget the bad situation and the fear of contagion what could increase the interest and desire for good and positive things.

The strategy of the owners or foremen of private properties to allow hikers and athletes get in their farms is plausible and laudable because that helps to manage the pandemic. That solidary decision is a resilient, generous, wise, and voluntary act that helps to reduce the chaos and make people feel better. People in distress and confined in their homes to avoid contagion appreciate that attitude of the farmers. Those who have opted for the activities described have been resilient, they have been moved towards simple, free and excellent activities that improve not only their health but also clear the mind of bad news from mass media and in social networks.

Practicing activities in open spaces is a great strategy to avoid exposure to the high luminosity of electronic devices used in closed spaces. According to [8], carrying out activities in open spaces helps to prevent or delay myopia. This is important in the context of the pandemic because COVID-19 has not only forced people to spend more time indoors but also to use electronic devices for longer. Students now spend more time in front of computers and cell phones due to virtual education. And something similar happens to workers who now have their homes as offices and are more exposed to the light of computer monitors. Thus, the recreational and sports 
activities observed in the routes of the periphery of Santo Domingo are also a strategy and a skill to keep the eyes healthy and reduce the risk of myopia.

\section{CONCLUSIONS}

The urban peripheries are those geographical spaces located between the urban and rural contexts, which represent a threshold between uses, customs, and landscapes of both. Within the urban imaginary, the peripheries become synonymous of life quality, with greater access to green spaces near the city. In the search for suitable places to carry out physical activities without social agglomerations, people activate the knowledge of their living spaces and identify suitable places such as nearby green areas or parks, neighborhoods with low population density and little crowded routes. The urban peripheries comply with many of these expectations and with the restrictive conditions of the COVID-19 pandemic.

The peripheries are increasingly integrated into the housing and recreational strategies of a part of the urban population, a situation currently favorable to the sanitary measures imposed for the management of the pandemic. The study area refers to the urban periphery located northwest of the Central Valley (around the cities of San Rafael, Santo Domingo and San Isidro, all three in the province of Heredia) but in other peripheral contexts there is also a transformation of functionalities in the current epidemiological situation, driven by the recognition of better environmental and recreational qualities.

The studied routes are being used by people to exercise, which allows them to properly manage the pandemic, leave the isolation and reduce both stress and anxiety. The periphery of the cities of Santo Domingo, San Pablo, San Rafael and San Isidro plays an important role in managing the stress and anxiety generated by adverse situations that include isolation and confinement. The sector studied is a good area for relaxation and recreation, useful for outdoor activities that reduce the impact of occupations carried out in closed spaces. The activity observed on the routes confirms that people have appealed to resistance and resilience to face COVID-19.

\section{REFERENCES}

[1] P. Fan, L. Yue, \& J. Chen, “Accessibility of public urban green space in an urban periphery: The case of Shanghai". Landscape and Urban Planning, 165, 177-192, 2017.

[2] Z. Venter, D. Barton, V. Gundersen, H. Figari, \& M. Nowell, "Urban nature in a time of crisis: recreational use of green space increases during the COVID-19 outbreak in Oslo". SocArXiv, Norway, 2020.

[3] R. Wynter, \& R. Light, "Body and Mind". History Today, Octuber Pgs 90-93, 2020.

[4] M. Ferreira, M. Irigoyen, F. Consolim-Colombo, J. Saraiva, K. Angelis, "Physically Active Lifestyle as an Approach to Confronting COVID-19", Arq Bras Cardiol. 2020; 114(4): 601-602., 2020.

[5] G. Duncan, A. Avery, E. Seto, \& S. Tsang, S. "Perceived change in physical activity levels and mental health during COVID-19: Findings among adult twin pairs". PLOS ONE, https://doi.org/10.1371/journal.pone.0237695 August 13.

[6] H. Shirvani, H. "Exercise and COVID-19 as an Infectious Disease". Iran J Med Sci July; Vol 45 No 4, Letters to Editor, 2020.

[7] M. Pelling, Vulnerability of Cities; Earthscan Publications Ltd, London Sterling, VA, 2003.

[8] P. Wu, C. Chen, K. Lin, C. Sun, C. Kuo, H. Huang, Y. Poon, M. Yang, C. Chen, J. Huang, P. Wu, I. Yang, H. Yu, P. Fang, C. Tsai, S. Chiou, Y. Yang, "Myopia Prevention and Outdoor Light Intensity in a School-Based Cluster Randomized Trial. Ophthalmology". 2018 Aug;125(8):1239-1250. doi: 10.1016/j.ophtha.2017.12.011. Epub 2018 Jan 19. PMID: 29371008. 